\title{
ВЕРХНЕПЛЕЙСТОЦЕНОВЫЙ РАЗРЕЗ КОЛЕШКИ (АРХАНГЕЛЬСКАЯ ОБЛАСТЬ) И ЕГО СТРАТИГРАФИЧЕСКОЕ ЗНАЧЕНИЕ
}

Морские и пресноводные верхнеплейстоценовые отложения на восточной окраине Балтийского щита широко представлены. С усовершенствованием палеонтологических и изотопных методов исследования стала очевидной принадлежность их к разным временным интервалам. В связи с этим институтами геологии Карельского филиала АН СССР и Академии наук ЭССР предприняты совместные работы по изучению разрезов, имеющих ключевое значение для решения спорных вопросов стратиграфии верхнеплейстоценовых отложений. Одним из наиболее перспективных участков, с которых были начаты работы, являются разрезы у д. Колешки, расположенные по среднему течению р. Ваги - притока Северной Двины. Морские межледниковые отложения здесь известны с конца прошлого столетия, но впервые обстоятельно они были изучены Б. П. Лихаревым (1933), который дал им название «двинские слои». В диагностике отложений Б. П. Лихарев исходил из фауны моллюсков. Изучение осадков методами диатомового и спорово-пыльцевого анализов было предпринято несколько позже А. П. Жузе и В. С. Порецким (1937) и И. М. Покровской (1937).

Возраст осадков данного участка окончательно не выяснен. Большинство исследователей сопоставляли их с нижнесеверодвинскими слоями, датированными по фауне моллюсков рисс-вюрмским межледниковьем. Иную оценку эти осадки получили у К. К. Воллосовича (1966, с. 28), который сильно занизил их возраст, синхронизируя осадки с падимейской свитой Большеземельской тундры, относимой им к нижнему - началу среднего плейстоцена. Микулинским межледниковьем оценивает эти отложения Э. И. Лосева $(1973$, с. 54$)$, изучавшая диатомовую флору по сборам К. К. Воллосовича.

Группа изученных авторами разрезов (рис. 1) находится на правобережном обрыве р. Ваги, в 3 км ниже устья р. Колешки. В одном из них (Колешки 1, рис. 2), были вскрыты: 


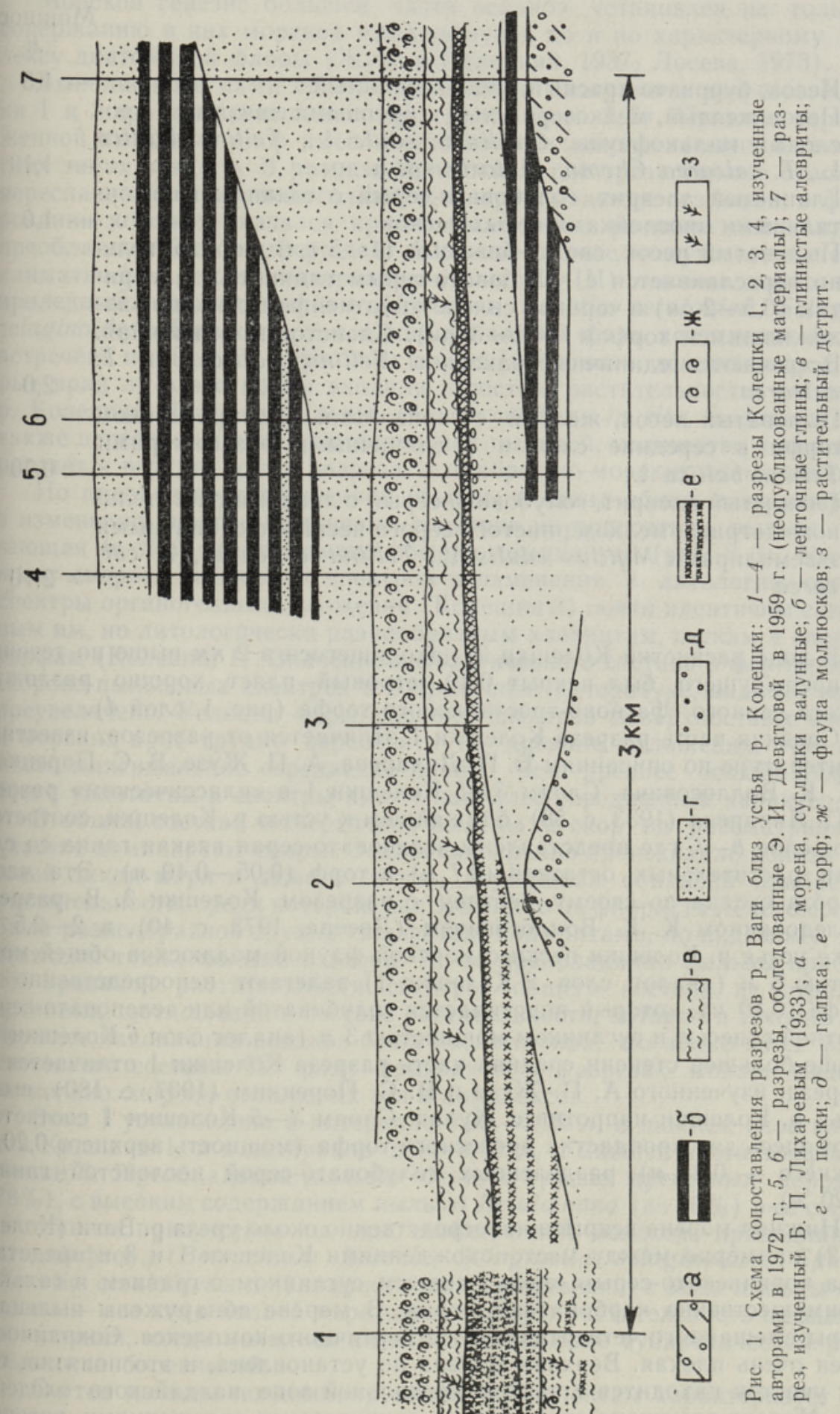

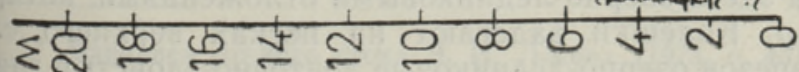


Мощность, M

1. Песок, буровато-красный, мелкозернистый $-1,5$

2. Песок желтый, мелкозернистый с крупными линзами и прослоями малакофауны: Cardium edule L., Tellina baltica L., T. calcarea Chemn., Astarte sp. и др. $\quad-1,10$

3. Глинистый алеврит, голубовато-серый с тонкими горизонтальными прослойками серых песков

4. Пылеватый песок, светло-бежевый $(1-5$ cм), горизонтально переслаивается с голубовато-серым глинистым алевритом $(0,5-2$ см) и черным, сильно уплотненным, хорошо разложившимся торфом $(0,5-3 \mathrm{~cm})$. Слоистость ритмичная. Встречаются единичные раковины Tellina baltica L.; $T$. calcarea

5. Пылеватый песок, желтый с горизонтальным прослойком торфа в середине слоя и с единичными экземплярами Tellina baltica L.

6. Глинистый алеврит, голубовато-серый с линзами растительного детрита, мелкозернистого серого песка и с единичными экземплярами Mytilus edulis L., Tellinabaltica L., T. calcarea

В ходе расчистки Колешки 3, находящегося в 2 км выше по течению от предыдущего, был вскрыт 0,40-метровый пласт хорошо разложившегося черного сфагново-тростникового торфа (рис. 1, слой 4).

Средняя часть разреза Колешки 1 отличается от разрезов, известных в литературе по описаниям Б. П. Лихарева, А. П. Жузе, В. С. Порецкого и К. К. Воллосовича. Слоям $3-5$ Колешки 1 в «классическом» разрезе Б. П. Лихарева $(1933$, с. 58$)$, ближайшем к устью р. Колешки, соответствуют слои $h-i$, где представлены зеленовато-серая вязкая глина со следами растительных остатков $(0,7 \mu)$ и торф $(0,05-0,40 \mu)$. Эта часть разреза сходна по своему составу с разрезом Колешки 3. В разрезе, обследованном К. К. Воллосовичем (Лосева, 1973, с. 40), в $2-2,5$ км ниже устья р. Колешки пески с морской фауной моллюсков общей мощностью $5 \mu$ (аналог слоя 2 Колешки 1) залегают непосредственно на торфе $(0,40 \mathrm{M})$, который подстилается голубоватой или зеленовато-серой плотной супесью и суглинком мощностью 3 м (аналог слоя 6 Колешки 1). В еще большей степени средняя часть разреза Колешки 1 отличается от разреза, изученного А. П. Жузе и В. С. Порецким $(1937$, с. 180$)$, выше устья р. Колешки напротив с. Кулич. Слоям $3-5$ Колешки 1 соответствуют здесь два пропластка древесного торфа (мощность верхнего 0,20 м, нижнего - 0,25 м), разделенных голубовато-серой неслоистой глиной $(1,20 M)$.

Нижняя морена вскрыта непосредственно около уреза р. Ваги (Колешки 2) примерно между местонахождениями Колешки 1 и 3 и представлена коричневато-серым очень плотным суглинком с гравием и галькой преимущественно карбонатных пород. В морене обнаружены пыльца и споры смешанного четвертично-дочетвертичного комплекса. Сохранность зерен очень плохая. Верхняя морена не установлена, и это понятно, так как участок находится в экстрагляциальной зоне валдайского оледенения. Морена замещена здесь озерно-ледниковыми отложениями, которые в 0,5 км ниже устья р. Колешки залегают на песках верхнего слоя Колешки 1. В ряде разрезов озерно-ледниковые ленточно-слоистые глины обнаружены также в основании разрезов (рис. 1). 
Морской генезис большей части осадков установлен не только по содержанию в них морской малакофауны, но и по характерному комплексу диатомовой флоры (Жузе и Порецкий, 1937; Лосева, 1973).

Выполненные нами спорово-пыльцевые диаграммы разрезов Колешки 1 и 3 взаимно дополняют друг друга (рис. 2,3). Привнос переотложенной пыльцы и спор имеет место во всех литологических и генетических типах осадков. В разрезе Колешки 1, где органогенные отложения переслаиваются или подстилаются и перекрываются осадками, в формировании которых сказался привнос материала речными потоками, они преобладают. Это подтверждает почти постоянное присутствие в спектрах климатически теплых интервалов (зоны II-III) пыльцы, свойственной приледниковым ландшафтам (Ephedra, Eurotia ceratoides, Selaginella selaginoides). Напротив, в осадках начальной фазы потепления (зона I) встречена пыльца термофильных пород (дуба, вяза, лещины и др.), которые вряд ли в это время входили в состав растительности на широте p. Колешки. Наличие пыльцы, залегающей не in situ, подтверждается также переотложенной дочетвертичной пыльцой, количество которой возрастает к верхней части разреза, в прибрежно-морских отложениях.*

Но привнос переотложенной пыльцы исказил общие закономерности в изменении спорово-пыльцевых спектров не полностью; пыльца, залегающая in situ, количественно обычно доминирует (рис. 2,3). Не искажают спорово-пыльцевых спектров и изменения в литологии осадков: спектры органогенных отложений (Колешки 3) почти идентичны синхронным им, но литологически разнообразным алевритам, пескам и слоистым торфам (Колешки 1). Значение литологического состава в формировании спорово-пыльцевых спектров в современной литературе, видимо, вообще преувеличено. Условия формирования спектров поверхностных озерных и морских проб трудно переносить на древние отложения, где имеет место максимальное осреднение пробы. Чем древнее осадки, тем они более уплотнены и спектры имеют наиболее осредненный характер.

В общем составе четвертичной пыльцы и спор на рассматриваемом участке доминируют споры. Осадконакопление происходило вблизи береговой линии моря и даже в лагуне, в условиях обильной прибрежной растительности, среди которой, как это видно из флористического состава, была разнообразной группа галофитов. Галофитами, по-видимому, представлены также полыни и злаки. Из-за преобладания пыльцы прибрежной травяной растительности спектры общего состава не отражают истинных соотношений в составе растительности, которая в течение всего периода накопления осадков была лесного типа, что видно из ее флористического состава. По ряду признаков в разрезах можно выделить несколько спорово-пыльцевых зон и комплексов.

Зона I установлена в интервале $0,00-0,95 \mu$, в нижнем слое алевритов Колешки 1 , и в интервале $0,00-0,13$ м, в нижней части торфов Колешки 3. Преобладание пыльцы берез в группе древесных пород (до $78 \%$ ), с высоким содержанием пыльцы Betula nana (до $45 \%$ ) в ее составе, постоянное присутствие пыльцы, свойственной осадкам приледниковых ландшафтов (Botrychium boreale, Selaginella selaginoides, Ephedra, Eurotia ceratoides и др.), нарастание одновременно с этим пыльцы ели и сосны - все это в полной мере характеризует растительность первых фаз потепления, когда началось активное вытеснение субарктической растительности бореальной.

Состав пыльцы по доминирующим компонентам характеризует фазу

* Влиянием речного стока Э. И. Лосева (1973, с. 43) объясняет также примесь пресноводных форм в морском комплексе днатомей. 
преимущественно березовых лесов. Биоценозы открытых местообитаний занимали весьма подчиненное положение. Сохранению в растительности таких ксерофитов и галофитов, как Eurotia ceratoides и Salsola kali, способствовало местообитание их в прибрежной зоне моря, которое в это время уже проникло в долину современной р. Ваги, но в районе р. Колешки было еще мелководным.

Следующая, зона II, в разрезе Колешки 1 выделяется в интервале 0,95-3,60 $\mu$ в отложениях, различных по генезису: в алевритах, песках и слоистых торфах. В разрезе Колешки 3 зоне II соответствуют средняя и верхняя части пласта торфа. Сходство спорово-пыльцевых диаграмм (рис. 2 и 3 ) проявляется в постоянном, довольно значительном содержании пыльцы ели $(5-27 \%)$, в обилии пыльцы сосны (до $50 \%$ в разрезе Колешки 1 и до $70 \%$ в разрезе Колешки 3), в преобладании во флористическом составе группы бореальных видов (Betula pubescenes, B. verrucosa, Picea, Pinus silvestris, Alnus incatra и др.), в большом разнообразии группы умеренно-термофильных видов (плаунов, гроздовниковых, ужовниковых, папоротников) и группы сибирских видов (Abies, Larix, Pinus cf. sibirica). Эти сочетания создают колорит своеобразной растительности фазы преимущественно хвойных лесов, в составе которых заметную роль играли элементы сибирской флоры.

В осадках Колешки 1, помимо доминирующих бореальных видов, обнаружено большое для широты р. Ваги количество пыльцы древесных широколиственных пород (до $10 \%$ ), из которых доминирует пыльца дуба и лещины (до $7 \%$ ). В осадках Колешки 3 встречаемость пыльцы термофильных видов незначительна. По-видимому, в разрезе Колешки 1 спектр термофильной пыльцы создавался не только растительностью непосредственных окрестностей местообитания, но и пополнялся пыльцой, принесенной издалека ветром и реками.**

О большом влиянии речного стока на формирование осадков Колешки 1 можно судить по их литологии (см. рис. 1). В местонахождении Колешки 3 отложения лагунного типа представлены торфом, привноса пыльцы извне не было и это определило разницу в составе спорово-пыльцевых спектров близко расположенных разрезов. Привносом пыльцы с других территорий следует объяснять и более высокое содержание пыльцы берез в разрезе Колешки 1 по сравнению с Колешки 3. Предположение о поступлении преобладающей части пыльцы из микулинских отложений исключено, так как в спектрах зоны II Колешки 1 отсутствует сопутствующий термофильным породам максимум пыльцы ольхи и лещины, характерный для диаграмм микулинского типа.

Явно переотложенной и чужеродной по отношению к доминирующему бореальному комплексу выглядит пыльца тундровых и северных бореальных видов (Selaginella selaginoides, Lycopodium pungens и др.) и пыльца ксерофитов (Ephedra, Eurotia ceratoides и др.). Есть основание полагать, что главным источником ее поступления были осадки предшествующей или даже более ранней эпохи, где эти виды были естественным компонентом (рис. 2 и 3 ).

Значительное участие переотложенной пыльцы в формировании спектров зоны II подтверждается содержанием переотложенной дочетвертичной пыльцы.

Одновозрастность осадков зоны II разрезов Колешки 1 и Колешки 3

** Все полноводные реки бассейна р. Ваги ориентированы с юга на север. Такой же меридиональной и субмеридиональной ориентировка их могла быть и в рассматриваемую эпоху. Область более широкого представительства термофильных пород в составе растительности простиралась южнее Колешки. 


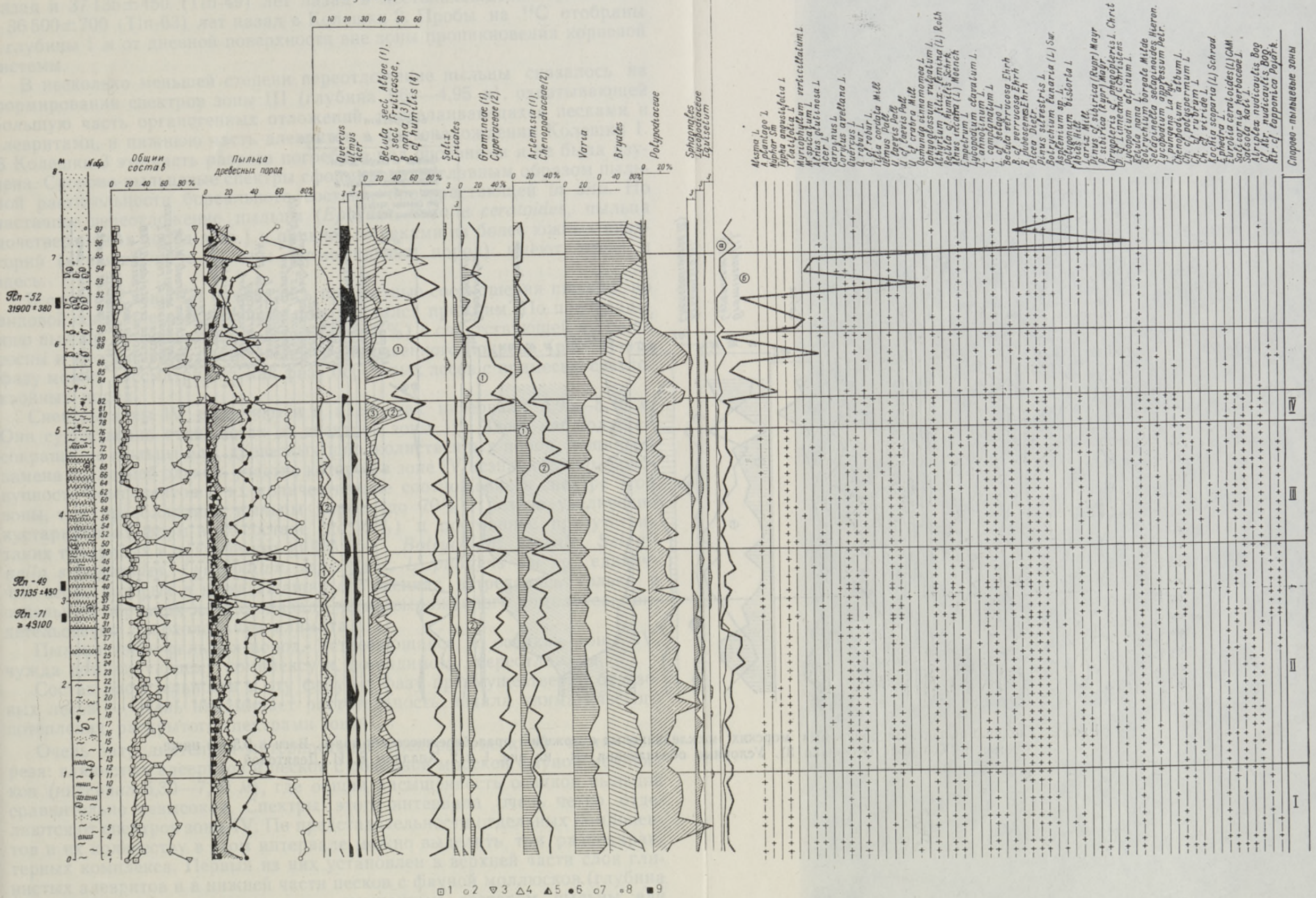

Рис. 2. Спорово-пыльцевая диаграмма морскнх межледниковых отложений правобережного обрыва р. Ваги в 1 км ниже устья р. Колешкі (Колешки 1). Анализы Э. И. Девятовой. Условные обозначения: 1 - пыльца древесных пород, 2 - пыльца трав и кустарничков, 3 - споры, 4 - пыльца ели, 5 - пихты, 6 - сосны, 7 - берез, 8 - пыльца кустарниковых берез, 9 - суммарный состав пыльцы древесных широколист венных пород. Остальные условные обозначения см. на рис. 1. 


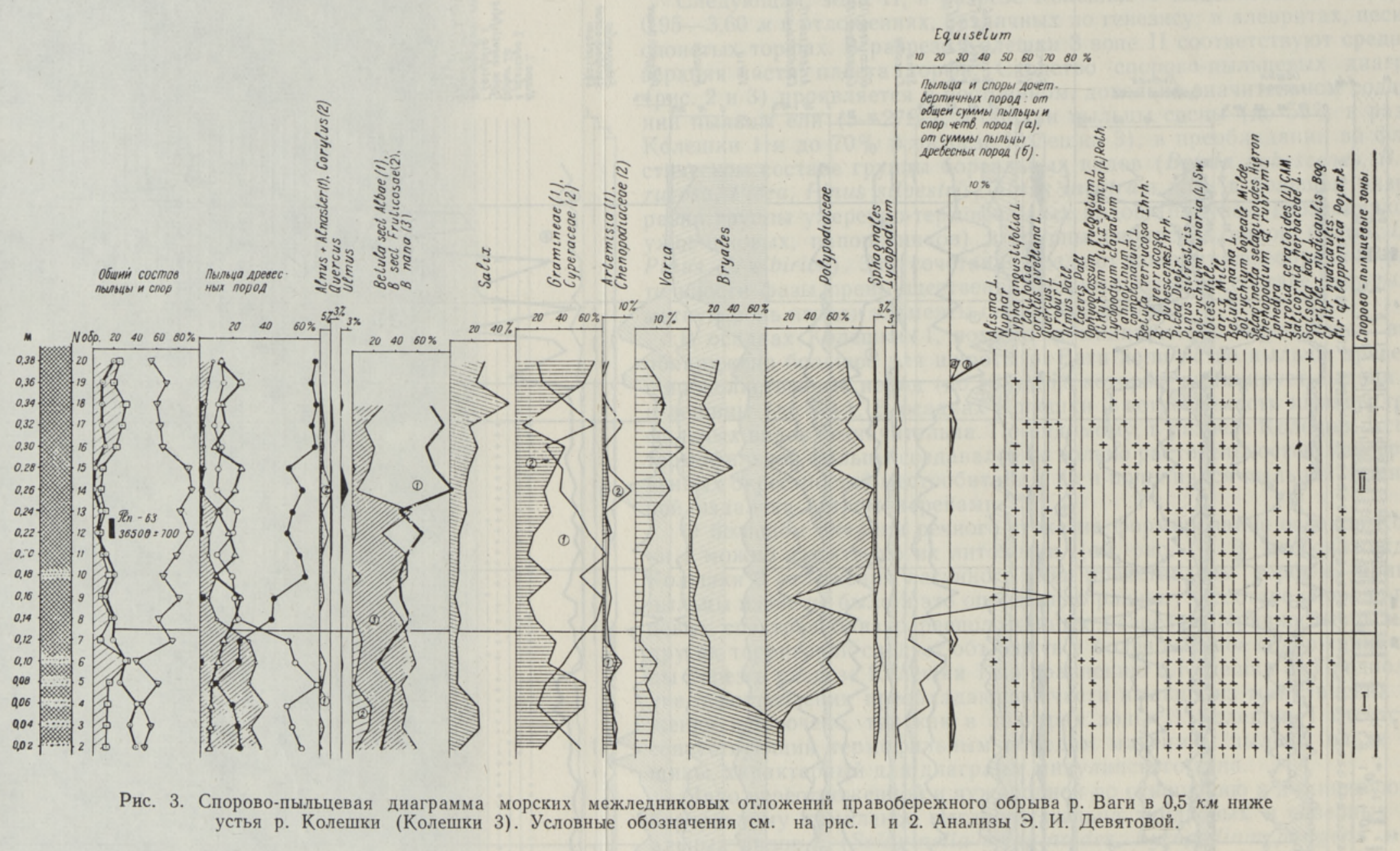


вполне обоснована абсолютными датировками: $\geqslant 49100$ (Tln-71) лет назад и $37135 \pm 450(\mathrm{~T} \ln -49)$ лет назад в местонахождении Колешки 1 и $36500 \pm 700$ (Tln-63) лет назад в Колешки 3. Пробы на ${ }^{14} \mathrm{C}$ отобраны с глубины 1 м от дневной поверхности вне зоны проникновения корневой системы.

В несколько меньшей степени переотложение пыльцы сказалось на формировании спектров зоны III (глубина $3,60-4,95$ м), охватывающей большую часть органогенных отложений, переслаивающихся песками и алевритами, и нижнюю часть алевритов в местонахождении Колешки 1. В Колешки 3 эта часть разреза погребена под оползнями и не была изучена. Спорово-пыльцевые спектры сформированы главным образом пыльцой растительности бореального состава, произрастающей in situ. Но частичное переотложение пыльцы (Ephedra, Eurotia ceratoides, пыльца дочетвертичных пород и др.) и привнос ее реками из более южных акваторий (какая-то часть пыльцы термофильных пород) имеют место и здесь.

В спектрах зоны III изменились процентные соотношения пыльцы, но видовой состав лесообразующих пород остался прежним. По преобладанию пыльцы древесных форм берез (43-47\%) с сопутствующей пыльцой сосны и мезофильной растительности напочвенного покрова (рис. 2) эту фазу можно рассматривать как фазу березовых лесов с примесью светлохвойных пород.

Спектры зоны IV выделяются в алевритах интервала 4,95-5,30 $\mathrm{M}$. Они существенно отличаются от спектров зоны III. Здесь наблюдается сокращение пыльцы ели, древесных широколиственных пород, лещины и замена последней ольхой, участие которой в зоне IV незначительно. Совокупность компонентов и их количественное соотношение в спектре этой зоны, т. е. преобладание пыльцы берез (до 70\%), резкое увеличение кустарниковых форм в их составе (до $32 \%$ ) и постоянное присутствие таких тундровых и арктических видов, как Botrychium boreale, Selaginella selaginoides, Lycopodium appressum, L. pungens и др., единичные зерна которых в нижележащих отложениях встречались только в отдельных образцах и не создавали четко выраженного комплекса, свидетельствуют о похолодании климата.

Пыльца термофильных пород, встречающаяся в осадках зоны IV, чужда доминирующему комплексу и, по-видимому, переотложена.

Состав растительности в эту фазу - фазу преимущественно березовых лесов - очень напоминает растительность начала климатического потепления, раскрытого спектрами зоны I.

Очень затруднительна интерпретация спектров верхней части разреза: глинистых алевритов и песков с обильной морской фауной моллюсков (интервал $5,30-7,00$ м), где общая насыщенность осадков пыльцой сравнительно невысокая. Спектры этого интервала очень четко отделяются от спектров зоны IV. По представительности отдельных компонентов и их количеству в этом интервале можно выделить три разнохарактерных комплекса. Первый из них установлен в верхней части слоя глинистых алевритов и в нижней части песков с фауной моллюсков (глубина $5,30-6,05 м)$; он характеризуется смешанным составом пыльцы ели $(4-47 \%)$, сосны $(35-62 \%)$ и берез $(18-48 \%)$ с двумя кульминациями первой и максимальным составом пыльцы сосны и берез между двумя пиками ели. Отсутствие четкой закономерности в изменении растительности видно и по флористическому составу.

Второй комплекс установлен в песках с обильной малакофауной на глубине 6,05-7,00 м. В него входит максимальное для разреза количество пыльцы древесных широколиственных пород (до 12\%), лещины (до

5 ENSV TA Toimetised K* G-2 1976 
$13 \%$ ) и ольхи (до $67 \%$ ). В полном соответствии с количественными соотношениями основных лесообразующих пород (береза, сосна, ель) с примесью широколиственных находится и флористический состав (рис. 2).

Третий комплекс установлен в песках на глубине $7,0-8,0$ м, где малакофауна уже исчезает. Максимум пыльцы берез $(47-81 \%)$ и в том числе кустарниковых форм $(20-46 \%)$ выводит спектры в категорию предледниковых. Однако здесь все еще много пыльцы древесных широколиственных пород $(5-6 \%)$, лещины $(2-5 \%)$ и ольхи $(37 \%)$.

Составы спорово-пыльцевых спектров всех трех комплексов, и в особенности второго (глубина 6,05-7,0 м), дают основание для выводов о принадлежности соответствующих им осадков ко времени значительного потепления. Тем более, что спектры этого интервала сходны по своему составу со спектрами отложений, изученных И. М. Покровской (1937) на р. Ваге выше устья р. Колешки, и в значительной степени напоминают спектры климатического оптимума второго позднеплейстоценового межледниковья Карелии (Девятова, 1972, 1973). Но в то же время для осадков этого интервала $(5,30-8,0$ м) характерно очень большое количество переотложенной дочетвертичной пыльцы. Это обстоятельство вызывает естественное предположение о возможности насыщения осадков также и четвертичной переэтложенной пыльцой. Однако по степени сохранности отделить переотложенную пыльцу от пыльцы, залегающей in situ, невозможно. Вывод о принадлежности осадков ко времени климатического оптимума подтверждает и абсолютная датировка $31900 \pm 380$ (Tln-52), полученная по раковинам моллюсков с глубины $6,50-6,70$ м. Эта дата закономерно завершает последовательный ряд датировок по разрезу (см. выше) и символизирует конец эпохи потепления и приближение нового оледенения.

Предвестниками похолодания являются и увеличение количества пыльцы Betula nana в третьем комплексе (глубина $7,0-8,0$ м) и явно доминирующее положение пыльцы берез в группе древесных пород. Но такой же пик $B$. nana с соответствующим ему характерным составом тундровых и северо-бореальных видов имеет место в спектрах зоны IV. Не разорван ли единый спектр пыльцы предледниковой растительности (зоны IV и третьего комплекса) обильным привносом пыльцы, переотложенной из микулинских отложений (первый и второй комплексы), что привело к пикам ели, дуба, вяза, лещины и ольхи?

На наш взгляд, до тех пор, пока этот интервал $(5,30-8,00$ м) не будет проконтролирован спорово-пыльцевыми анализами и абсолютными датировками на других аналогичных разрезах р. Ваги, окончательная оценка эпохи накопления осадков верхней части разреза Колешки 1 и соответствующих им спорово-пыльцевых комплексов невозможна.

По совокупности спорово-пыльцевых спектров, флористическому составу и всей серии радиоуглеродных датировок осадки, вскрытые на p. Ваге близ устья р. Колешки, не могут оцениваться микулинским, или в более широком понимании рисс-вюрмским межледниковьем, а тем более нижне- или среднеплейстоценовым межледниковьем. По всей вероятности, данные осадки принадлежат к средневалдайскому потеплению. На основании радиоуглеродных датировок эпоху накопления осадков на р. Ваге условно можно сопоставить с интерстадиалом хенгело в Нидерландах (Hammen и др., 1971) и средней частью каргинского межледниковья в Сибири (Кинд, 1971). Примерно этим же временем датируется также межледниковая трансгрессия на Кольском полуострове (Евзеров, 1970; Пуннинг, 1971). По многим особенностям спорово-пыльцевой диаграммы разрез Колешки 1 сходен со средневалдайскими отложениями в Карелии (Девятова, 1972, 1973) и с разрезом Гражданский проспект в 
Ленинграде (Вигдорчик и др., 1970; Геоморф. и четв. отл. Сев.-Зап. Европ. части СССР, 1969). Но однозначное решение вопроса о таксономическом ранге и стратиграфическом положении разреза Колешки возможно лишь после тщательного изучения других межледниковых и межстадиальных разрезов Прибеломорья. Но одно уже ясно: геология и стратиграфия позднего плейстоцена в этом районе значительно сложнее, чем это предполагали до сих пор.

\section{ЛИ Т Е Р А Т РА}

Вигдорчик М. Е., Ауслендер В. Г., 3 наменска я О. М., Долуханов П. М. 1970. Новые радиоуглеродные датировки озерных осадков на северо-западе РСФСР и геохронологическая шкала последнего оледенения. История озер. Тр. Всесоюз. симпоз. по основным проблемам пресноводных озер (25-29 мая 1970 г.), 2, Вильнюс.

В оллосович К. К. 1966. Мат-лы для познания основных этапов геологической истории европейского северо-вюстока в плиоцене - среднем плейстоцене. Геол. кайнозоя севера Европ. части СССР. М.

Геоморфология и четвертичные отложения Северо-Запада Европейской части СССР. 1969. Л.

Девя то в а Э. И. 1972. Палинологическая характеристика верхнечетвертичных отложений Карелии. В сб.: Четверт, геол. и геоморф. вост. части Балт. щита. Тр. Ин-та геол., вып. 13. Л.

Д е в я т о в а Э. И. 1973. Некоторые особенности состава спорово-пыльцевых спектров верхнеплейстоценовых отложений юго-восточной окраины Балтийского щита. В кн.: Палинология плейстоц. и плиоц. Тр. III Международ. палинол. конфер. М.

Е в зеро в В. Я. 1970. К вопросу о возрасте межледниковых отложений Кольского полуострова. Мат-лы по геол. и металлогении Кольского п-ва. Апатиты.

Ж узе А. П., По.рецкий В. С. 1937. Диатомовые межледниковые отложения по p. Ваге. Тр. Сов. секц. междунар. ассоц. по изуч. четв. периода. Вып. 1. Л.

К и нд Н. В. 1971. Изменения климата и оледенения в верхнем антропогене (абсолютная геохронология). Автореф. докт. дис. М.

Л и х а ре в Б. П. 1933. Общая геологическая карта Европейской части СССР. Лист 69. Шенкурск - Вельск. Тр. Всес. геол.-развед. объединения НКТП СССР, вып.
240. Л.-М.

Л осев а Э. И. 1973. Диатомовые водоросли отложений бореальной трансгрессии в бассейне р. Ваги. В кн.: Геология и палеонтология плейстоцена сев.-востока Европ. части СССР. Сыктывкар.

Покровская И. М. 1937. Некоторые данные микропалеоботанического изучения межледниковых отложений pp. Сев. Двины и Ваги. Тр. Сов. секц. междунар. ассоц. по изуч. четв. периода. Вып. 1. Л.

П унни н г Я.-М. 1971. Об абсолютном возрасте второго позднеплейстоценового межледниковья на территорин северо-западной части Русской равнины. Изв. АН ЭССР, Хим. Геол., 20, № 3.

H a m m en T., W i jmstra T. A., Z a g w i j n W. H. 1971. The floral record of the late Genozoic of Europe. In: The late Genozoic glacial ages. Yale University Press.

Институт геологии
Карельского филиала АН СССР
Институт геологии

Поступила в редакцию $25 / \mathrm{X} \quad 1974$

Академии наук Эстонской ССР

\section{E. DEVJATOVA, J.-M. PUNNING}

\section{ULEMPLEISTOTSEENI SETTED KOLESKKA LÄBILÕIKES (ARHANGELSKI OBLAST) JA NENDE STRATIGRAAFILINE TOLGENDUS}

Arvukad meresetete läbilõiked Arhangelski oblastis pakuvad väärtuslikku materjali ülempleistotseeni kronostratigraafiliste probleemide lahendamisel. Autorid uurisid läbilöikeid Vaga jōe paremal kaldal (joon. 1). Limnoglatsiaalsete liivadega kaetud aleuriidid sisaldavad hulgaliselt subfossiilsete molluskite kodasid ning ka turba vahekihte. Setteid uuriti palünoloogilisẹlt (joon. 2, 3) ning osa proovide vanus määrati radioaktiivse süsiniku 
meetodil. Koostatud palünoloogilisel diagrammil võib eristada iseloomulikke komplekse ja tsoone, mis võimaldavad hinnata klimaatiliste muutuste üldtendentsi. Klimaatilise optimumi ajal ladestunud setete vanuseks saadi $31900 \pm 380$ aastat. Allpool lasuvate turbakihtide vanused on vastavalt $36500 \pm 700$ ja $37135 \pm 450$ aastat. Palünoloogilise analüüsi, floristilise koostise ja ${ }^{14} \mathrm{C}$ dateeringute põhjal võib setete kujunemise ajaks pidada valdai jäätumise vältel esinenud soojaperioodi, mis on samastatav hengelo interstadiaaliga Hollandis ja kargini interglatsiaaliga Siberis.

\section{E. DEVYATOVA, J.-M. PUNNING}

\section{UPPER PLEISTOCENE DEPOSITS IN THE KOLESHKA PROFILE (ARKHANGELSK REGION) AND THEIR STRATIGRAPHIC INTERPRETATION}

The numerous profiles of marine deposits in Arkhangelsk Region offer valuable material for the solution of chronostratigraphic problems of the Upper Pleistocene. The profiles on the right bank of the Vaga River (Fig. 1) were studied by the authors. The aleurites covered with limnoglacial sands contain abundantly shells of subfossil molluscs and also interlayers of peat. The deposits were examined palynologically (Figs 2 and 3), and the age of a number of samples was determined by the radiocarbon method. In the palynological diagramme composed, one may differentiate characteristic complexes and zones that enable to determine the general tendency of climatic changes. The age of the strata deposited during the climatic optimum was assessed as $31,900 \pm 380$ years. The ages of the underlying peat layers are correspondingly $36,500 \pm 700$ and $37,135 \pm 450$ years. On the basis of palynological analyses, floristic composition and ${ }^{14} \mathrm{C}$ datings, it may be supposed that the time of the formation of those deposits coincided with the warm period that occurred during the Valdai glaciation and corresponded to the Hengelo interstadial in Holland and the Kargin interstadial in Siberia. 